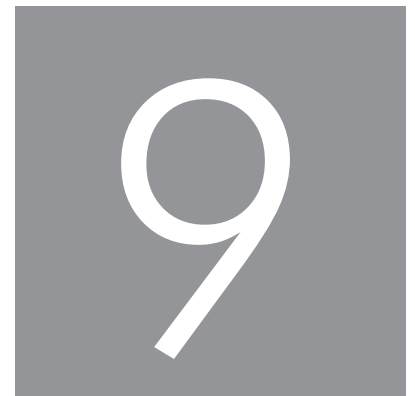

\title{
FACTORS THAT PROMOTE OR HINDER THE VOICE OF THE THIRD SECTOR IN PUBLIC SERVICE DELIVERY
}

\section{PERSPECTIVES ON THE BATHOPEFPRINCIPLES}

Pulane Pitso

\begin{abstract}
Although Batho Pele ('People First') principles are central to public service transformation, they are not being implemented adequately at present. Improving public services, which requires authentic dialogue with a balanced voice from all sectors of civil society, is critical. However, the third sector has received little attention in this regard. The qualitative research design of the study reported in this chapter constituted a focus group discussion among eight managers from seven non-profit organisations as part of the third sector and representatives of the citizens. The implementation of and compliance with Batho Pele principles by public servants remain challenging, partly due to a lack of supervision and accountability within government. Change in the organisational culture of the public service is therefore crucial. Moreover, a joint effort from diverse sectors within civil society could yield even better results. Non-profit organisations continually seek to interact with government on the challenges experienced by citizens, to advocate for community interests and needs, and to hold government accountable. It is suggested that internal weaknesses and operational challenges within the system be removed, while government shifts from perceiving citizens, and non-profit organisations in particular, as 'mere' sources of information. Instead, they should be regarded as active partners in improving service delivery.
\end{abstract}




\section{INTRODUCTION}

Authentic dialogue marked by a balanced voice from all sectors of civil society is crucial to improving public service. The traditional concept of public administration is gradually shifting from a system of distinct sectoral boundaries (public, private, non-profit, higher education) toward distributed governance with the different sectors as partners, including non-profit organisations (NPOs) as one of the bodies in the third sector (Choudhury \& Ahmed 2002:562).

This chapter focuses on the importance and value of the third sector's voice on service delivery, with specific reference to the Batho Pele principles. In South Africa, the imperative for the delivery of quality public service is rooted in the eight principles espoused in the White Paper on the Transformation of Public Service (RSA DPSA 1997), namely consultation, service standards, access, courtesy, information, openness and transparency, redress and value for money. The Batho Pele principles imply that all citizens are provided with public services based on certain 'people attributes', and with accountable and transparent governance (Mulaudzi \& Liebenberg 2013:142). Failure to implement the Batho Pele principles is at the heart of poor service delivery (Hesma \& Roberts 2007:12; RSA DPSA 2008:3). Since 2004 South Africa has experienced an unprecedented wave of public protests against poor service delivery (Idasa 2010:2), with the Free State province also affected (Coetzee 2005:154). Despite intense endeavours directed at improving service delivery, significant challenges remain (Luthuli 2009:460).

Reasons for the protests include a lack of consultation and communication between the citizens and government (Napier 2008: 172), a lack of transparency on processes and information (Vyas-Doorgapersad \& Ababio 2006:392), insufficient attention to the views and needs of the citizens, and a lack of public participation (Coetzee 2010:84; Idasa 2010:3-4), indicating government's failure to implement the Batho Pele principles. Although government is primarily responsible for addressing service delivery challenges, extensive collaboration with various sectors (including higher education institutions and the third sector) is more likely to yield better results. However, the literature shows that the third sector as an emergent global institution has received little attention thus far (Choudhury \& Ahmed 2002:581).

Third sector organisations are representatives of the people at grassroots level and their primary voice in the fight for social, economic and political justice. Although they often work in partnership with higher education institutions and the private and public sectors, they operate outside the confines of such bodies; therefore they have unique insight into those sectors. The voice of the third sector can therefore not be undermined, and NPOs in this sector should be given the platform and opportunity 
to voice their challenges and find solutions for effective and sustainable development in public service delivery.

This chapter reports on a study aimed at identifying the factors that either promote or hinder the voice of the NPOs. The participating NPOs in the third sector were allowed to express the challenges they face and to voice their experiences, their needs and their expectations in terms of the Batho Pele principles. The purpose of giving such NPOs a voice is to enable government not only to be fully responsive to the needs of NPOs as both partners and clients, but also to address its own challenges based on contributions from the NPOs. This reciprocal sharing of knowledge between the NPOs and government is indispensable for mutual enablement and empowerment. It is therefore argued that by identifying the factors that either promote or hinder the voice of the third sector regarding service delivery, a platform for authentic dialogue can be created to enhance the collaborative relationships between the third sector, the public service sector and other stakeholders.

The remainder of this chapter contains the literature review of the citizens' voice in participation, as well as a description of the context of the study. The chapter concludes with details of the findings of the focus group discussion in this qualitative study highlighting factors hindering and promoting service delivery.

\section{LITERATURE REVIEW}

There are a number of enablers for improved public service delivery (Ngowi 2009; Nyamukachi 2004; Wilkins 2001); however, the focus here is on the Batho Pele principles as a central component of public service transformation. The Batho Pele initiative redirects the focus of the public service to the needs of the citizens. The focus of this initiative on the citizen makes it a crucial enabler towards improved public service delivery, because the government is about serving the people.

However, insufficient attention to the voice of the citizens is a barrier to improved service delivery (Coetzee 2010:84; Idasa 2010:3-4). Therefore, the literature review focuses on the significance of the citizen's voice in authentic service delivery related dialogue.

\subsection{Significance of the citizens' voice in authentic dialogue towards improved public service delivery}

Constitution of the Republic of South Africa, Act no 108 of 1996 (RSA 1996) upholds that the provision of decent public service is a rightful expectation of all citizens, thus the state of public service delivery in South Africa has constitutional and human rights 
implications. Consequently, it is crucial for public service delivery to be improved and it needs to be expedited in a dynamic and ongoing process (Kroukamp 1999:329). Ghaus-Pasha (2004:33) emphasise that an "inclusive partnership-building strategy" is required. This strategy implies that representativeness of the needs of all sectors of civil society is essential for the efficient transformation and improvement of public service delivery (Choudhury \& Ahmed 2002:562; Mubangizi 2005:633; RSA DPSA 1997).

In fact, whether the third sector is engaging with the public sector or with higher education, with reference to the overarching theme of this book, authentic dialogue marked by a balanced voice from all sectors in the engagement remains crucial. Consequently, the importance of authentic dialogue in all third sector engagements with higher education cannot be overemphasised. The mission of creating an enabling platform for both higher education and the third sector, through reciprocal knowledge sharing and collaboration, cannot be completely accomplished outside the context of fully fledged authentic dialogue.

Furthermore, there seems to be certain dilemmas in terms of the third sector voice, particularly in the public service (Choudhury \& Ahmed 2002:581; Macmillan 2010:6-7). These dilemmas are not, however, limited to the public service. Even within the South African higher education sector there often seems to be a limited understanding of third sector organisations, as well as their functioning, the challenges they face, and the forms of capacity building they might require. The limited understanding regarding third sector dynamics suggest, inter alia, that the voice of the sector, with particular reference to NPO staff and community members they serve are often less audible (Alperstein 2007; Du Plessis \& Van Dyk 2013; Nduna 2007). Therefore, although this chapter focuses on engagement between the third sector and public service, the findings of the study may shed some light on - and even raise awareness of - other sectors in society involved in various forms of engagement with the third sector, particularly with regard to factors that could hinder or promote the voice of third sector organisations.

Moreover, authentic dialogue during higher education-third sector engagement efforts is essential, as higher education institutions in many countries, and particularly in the South African context, rely largely on collaboration and partnership with organisations within the third sector of society as sites for academic student service placement, as well as community-based contextual research (Thomson, Smith-Tolken, Naidoo \& Bringle 2008:227-228). However, the strength of this partnership and engagement between the third sector and higher education is dependent on mutual enablement and authentic dialogue where the voices of both sectors are heard. 
This chapter contributes towards placing higher education in a better position to take precautionary measures in terms of factors that could hinder the voice of the third sector. Simultaneously it places higher education in a position to seek ways of strengthening and deepening engagement between higher education institutions and organisations of the third sector, by focusing on the factors that could promote the voice of the third sector.

\subsubsection{Citizen participation as a constitutional imperative}

The voice of the citizens as an integral part of civil society in respect of service delivery is indispensable (RSA DPSA 1997; World Bank 2004:1). Moreover, citizens - as the clients of government - experience the resultant effects of the services delivered and therefore can contribute considerably towards propositions related to public service improvement. Citizen participation is enforced by the Constitution (RSA 1996) and is regarded as one of the cornerstones of good governance (Mutahaba 2006:282; Napier 2008: 166). Therefore, notwithstanding the dilemmas of citizen participation, which include citizen ignorance, low literacy levels and unwillingness to participate (Kroukamp 1999:330-333), it remains a constitutional imperative and cannot go unheeded.

\subsubsection{Dilemmas of citizen participation}

While the voice of the citizens is deemed essential to improved public service delivery, the participation of the citizens, especially at grassroots levels, is often neglected (Coetzee 2010:84; Idasa 2010:3-4; World Bank 2004:9). They experience the lowest level of consultation, redress, openness, relevant information and courtesy (Hesma \& Roberts 2007:14), since they often have limited opportunities to voice their concerns and experiences in terms of service delivery. This calls for alternative interventions towards strengthening the voice of the citizens, especially those at grassroots level (Ghaus-Pasha 2004:30; World Bank 2004:8). This call becomes even more critical to a democratic government of a developing state such as South Africa, as it is characterised by its ability to provide a space for the voice of all, including the poorest of the poor.

\subsection{The third sector as representative of the voice of the citizens}

One of the means of stimulating the emergence of an active and reflective citizenry, especially in the implementation of Batho Pele principles, is by reinvigorating the third sector's participation and voice (Ghaus-Pasha 2004:30; Mubangizi 2005:646; Sibanda 2011:815). 
Such a Batho Pele initiative by itself cannot address problems such as poverty, crime, social injustice and unemployment; and institutional reforms on systems, structures and policies are not sufficient to guarantee effective transformation and improvement of public service delivery. Therefore, in principle, an improvement in public service delivery requires sufficient attention to both the hard enablers (such as sector-specific mandates, systems, structures and policies) and soft enablers (Batho Pele principles) towards an effective and efficient administrative machinery. In this instance a wide range of the reasons given as justification for public protests against poor service delivery reflects a lack of implementation of the Batho Pele principles. Hence, one of the aims of the chapter is to make the voice of the third sector (as representatives of marginalised clients) heard on the Batho Pele principles.

\subsubsection{Distinct role of the third sector in the social environment}

Taking into account the diversity of sectors in a civil society, the question may be posed: Why the focus on the third sector? The third sector as an institution outside the realm of government and distinct from other sectors (Mubangizi 2005:646) seems to have certain comparative advantages in dealing with social, political and environmental issues. It is closely connected to the communities it serves; it has a relatively strong relationship with the people at grassroots level and is perceived as having gained the trust of the citizens, which is not always the case when it comes to government. Furthermore, the third sector is a critical contributor to, and participant in, the social and economic development of communities (Ghaus-Pasha 2004:9), playing an intermediary role between government and the citizens (Ndou 2013:192) and promoting the principles of good governance (transparency, openness, responsiveness and accountability) (Ghaus-Pasha 2004:3), thus possessing 'moral authority' in society (Ghaus-Pasha 2004:25; HM Treasury Report 2007:5). In response to the question posed earlier (Why focus on the third sector?), it is evident that the significant role and position of the third sector in the civil society place it in a favourable position to act as the representatives of the people at grassroots level.

\subsubsection{Dilemmas of the third sector 'voice' in public service delivery}

Over the past three decades the third sector has played an increasingly influential role in public service delivery, particularly in developed countries and especially through the formulation of public policy at both domestic and international level. In contrast, however, the role of the third sector in developing countries (eg South Africa) is seen as being restrained, undermined and given little attention (Choudhury \& Ahmed 2002:581). Traditionally, the third sector focused on the delivery of services at the expense of its 'voice', driven by a developing agenda to transform public 
service by utilising broader suppliers of a mixed economy (Macmillan 2010:6-7). The constraints encountered by the third sector in developing countries, inter alia, financial, technical and capacity constraints, narrow agendas and exclusive memberships (Ghaus-Pasha 2004:18, 33), could prevent the voice of the third sector from being heard.

Interventions that could promote the voice of the third sector, on the other hand, include an enhanced consultation process in line with greater government transparency and responsiveness, investment in capacity building support, the review of the nature of funding arrangements that may limit the third sector's independence, the creation of a new advisory structure for the third sector to express its voice, and the enforcement of policies, acts and regulations advocating the voice of the third sector in social society (HM Treasury Report 2007:17-19).

Kroukamp (1999:335) defines citizen participation as the mobilisation of the voice of the citizens by creating a platform for them to share their views, challenges and needs in terms of public service delivery. However, that voice becomes more effective when information is shared, when participation outcomes affect decision-making processes (Napier 2008:166; World Bank 2004:8), and all sectors are prepared to be objective and learn from one another (Clark 1993). To promote the voice and bargaining power of the third sector, Ghaus-Pasha $(2004: 24,27)$ recommends sound partnerships, the amalgamation of resources, and the coordination of efforts among different bodies within the third sector. In addition, Clark (1993) emphasises the importance of inclusive membership in government forums focusing on service delivery issues.

\section{CONTEXT OF STUDY}

The research was of an exploratory nature, which necessitated the use of a qualitative research design in the gathering of data. The qualitative method involves an in-depth study using face-to-face techniques to collect data from people in a natural setting (McMillan \& Schumacher 2010:321).

\subsection{Data collection method}

The focus group discussion (FGD) was employed as a qualitative data collection method to collect in-depth data about the participants' insights. FGD is an enabling tool designed to create a better understanding of people's feelings and perceptions about a particular issue (Greeff 2005:299; Nieuwenhuis 2007b:90). More profoundly, focus groups create a platform to not only listen to people, but also to learn from others (Greeff 2005:300). 
Greeff (2005:299) contends that participants in a focus group are selected because they have certain characteristics in common that relate to the phenomena under study. In this study, the inclusion criteria were based on the participants' participation in an NPO that is considered to be an institution close to the community it serves. Being geographically situated in Bloemfontein in the Mangaung Metropolitan Municipality area (Free State province), all the NPOs also had a relationship of some sort with the University of the Free State. A description of the participants in the relevant FGD is provided in Table 9.1.

TABLE 9.1 Description of participants in the focus group discussion

\begin{tabular}{|c|c|c|c|c|}
\hline Participant & Position & NPO & $\begin{array}{l}\text { Primary focus } \\
\text { area }\end{array}$ & $\begin{array}{c}\text { Relationship with government } \\
\text { department(s) }\end{array}$ \\
\hline Participant 1 & Manager & $\mathrm{NPO \#} 1$ & Homeless people & No direct or indirect relationship \\
\hline Participant 2 & Manager & $\mathrm{NPO \# 2}$ & $\begin{array}{l}\text { Inner city residents, } \\
\text { street children and } \\
\text { families }\end{array}$ & No direct or indirect relationship \\
\hline Participant 3 & Manager & $\mathrm{NPO \# 3}$ & $\begin{array}{l}\text { Community } \\
\text { (mainly youth) }\end{array}$ & $\begin{array}{l}\text { Department of Social Development } \\
\text { Department of Education }\end{array}$ \\
\hline Participant 4 & Manager & $\mathrm{NPO \# 4}$ & $\begin{array}{l}\text { Drug and } \\
\text { substance abuse }\end{array}$ & $\begin{array}{l}\text { Department of Social Development } \\
\text { Department of Education } \\
\text { Department of Correctional Services }\end{array}$ \\
\hline Participant 5 & Manager & NPO\#5 & Legal assistance & No direct or indirect relationship \\
\hline Participant 6 & Manager 1 & NPO\#6 & Home-based care & Department of Health \\
\hline Participant 7 & Manager 2 & $\mathrm{NPO \# 6}$ & Home-based care & Department of Health \\
\hline Participant 8 & Manager & $\mathrm{NPO \# 7}$ & $\begin{array}{l}\text { The elderly (aged } \\
60 \text { years and } \\
\text { upwards) }\end{array}$ & $\begin{array}{l}\text { Department of Social Development } \\
\text { Department of Health } \\
\text { Department of Education }\end{array}$ \\
\hline
\end{tabular}

Five of the seven selected NPOs had a relationship with one or more government departments, with the Department of Social Development and the Department of Education being the most prominent. Those NPOs classified as having no direct or indirect relationship with a government department participated as clients of government in their own right, but also as the voice of the citizens they serve.

Since most qualitative methods rely on purposive sampling (Greeff 2005:304; Nieuwenhuis 2007b:90), purposive sampling was employed to allow the researcher to select participants with specific knowledge of the phenomena being studied (Berg 2009:50-51; Creswell \& Plano Clark 2007:1 12; Maree 2007:178; McMillan \& Schumacher 2010:138). 


\subsection{Procedure}

A focus group script was developed, after which the FGD took place. Approximately 120 minutes in duration, the interview was conducted according to the following procedure:

- A study information document and informed consent form were developed, and all participants were guided through the documents and given an explanation of the aim and purpose of the FGD.

- All participants signed and submitted informed consent forms, confirming their voluntary participation in the FGD.

- Participants were seated in a circle, giving each an equal opportunity to participate fully.

- A focus group script, with specific questions focusing on the views and experiences of the NPOs, was used to guide the discussions. A funnel structure format or a questioning route strategy was used, as described by Greeff (2005:308), Krueger and Casey (2009:38-41) and Nieuwenhuis (2007b:91), whereby the researcher commenced with a broad and less structured set of questions to put the participants at ease. The concluding section was narrow, covering questions pertinent to the phenomena under study.

- The FGD was electronically recorded and transcribed verbatim directly after being concluded.

- During the FGD, a tape recorder operator and an assistant facilitator were present to record their own observations in order to enhance the credibility of the study (Nieuwenhuis 2007b:93).

\subsection{Analysis of data collected}

The data from the FGD conducted with the NPOs were analysed, classified and summarised on the qualitative content analysis. Corbin and Strauss (2008:66) and Nieuwenhuis (2007a:101) explain content analysis as a process identifying themes in the text in order to understand and interpret the raw data. In this particular study, data were analysed by commencing with an initial reading of the text, dividing it into segments based on the study's objectives, and then creating codes and themes (Creswell 2005:238).

\section{FINDINGS AND DISCUSSION}

The dominant themes emanating from the FGD with the selected NPOs were identified during the qualitative content analysis, and these are presented and discussed in the subsequent section. These themes related to the implementation, 
promotion of and hindrances to Batho Pelo principles. Verbatim quotes are used where applicable, and only significant remarks are presented as recorded.

\subsection{Views of non-profit organisations regarding the implementation of Batho Pele principles by public servants}

The categories related to implementation range from consultation to information provision, openness and transparency.

\subsubsection{Consultation}

Although, as certain participants indicated, it is "mandated by law" and an "obligation of government" that citizens be consulted about the level and quality of public service, this is apparently seldom the case. Many participants claimed that "there is absolutely no consultation" between government and the citizens. Some of the challenges related to consultation are expounded below.

One of these challenges is that there is no feedback loop on changes. There are even more negative implications for NPOs when amendments are made to policies or funding without any consultation. One participant commented:

We would like to know if there is a change in the policy or in the amount of money that they [government] are going to subsidise. Our experience is that we just hear that they [government] have decided and then you see in the amount that you get.

Poor planning by NPOs was a further challenge. The participants highlighted that lack of consultation on the part of government poses a challenge, especially when it comes to proper planning and internal control measures to address any financial adjustments or policy changes by government. In general the participant's description of consultation as a one-way communication channel from government is contradictory to the view of consultation as a constitutional imperative (RSA 1996) and one of the cornerstones of good governance (Mutahaba 2006:282; Napier 2008: 166).

All the NPOs considered themselves to be in partnership with government, with the expectation of a balanced voice from all partners (Choudhury \& Ahmed 2002:562; Mubangizi 2005:633; RSA DPSA 1997). This relates to the concept of inclusive partnership building, as referred to by Ghaus-Pasha (2004:33). As such, this implies that there is a need for government to make an effort to hear and understand the voice of the citizens and not only impose solutions and decisions. When there is no regular consultation with the citizens or where there is only one-way communication, 
authentic dialogue characterised by a participative and collaborative relationship between government and the citizens will remain a challenge.

\subsubsection{Service standards}

Lack of awareness of citizens' rights, public ignorance, fear of victimisation by public servants, and lack of supervision and accountability were identified as some of the contributing factors towards the challenges related to service standards in the public service.

The first of these challenges was lack of awareness of citizens' rights. The provision of information on service standards involves government "informing the community of the powers and the rights they are entitled to" as noted by one participant. However, in reality there seems to be a lack of openness and transparency when it comes to providing citizens with information on service standards.

Public ignorance or, as Kroukamp (1999:330-333) states, citizen ignorance is one of the dilemmas of citizen participation. Although service standards are on display at certain service points, citizens have a tendency to ignore the information:

I have seen it so many times that [Batho Pele] principles are put there on walls in certain places and not everywhere but the people don't take to heart and they don't challenge the service standards.

Fear of victimisation by public servants influences consultation. In cases where public servants deviate from the promised service standards, citizens are often unwilling to challenge the situation due to fear of victimisation:

The thing is if you stand up and say you are supposed to give me this service then they victimise you and treat you even more badly.

Lack of supervision and accountability may be problematic. Officials in key positions do not always hold public servants accountable for their actions, and strengthening the role of management appears to be a possible solution:

They [public servants] don't get supervision so they are on their own, they do as they please, no checks, they don't send reports. But if supervisors who enforce [Batho Pele] principles and say you treat a client or a member of the public as follows and he or she must know there are ears and eyes watching them.

Discrepancies between the stipulated service standards and the actual performance of public servants may point to certain challenges in terms of the competency levels of public servants. Should this be the case, it implies that government has a role to play in employing officials who are capable of meeting the required standards. 


\subsubsection{Access}

Access to public service remains a significant concern for citizens. Poor planning, shortage of staff, judgemental attitudes or discrimination on the basis of colour, race, gender or age, lack of adherence to official working hours, and lack of supervision at the coalface of service delivery were pointed out as some of the contributing factors to access related challenges in government.

\subsubsection{Courtesy}

The seemingly indifferent attitude of public servants in their interaction with citizens appears to be a major concern. In this instance the participants made comments such as: "We have a lot of rude service providers, blatant[ly] rude", and "their approach is the breakdown of humanity and dignity". It is therefore important to recognise that in the South African context, failure to safeguard the human dignity of citizens will always pose a challenge in the successful transformation of public service delivery. Shortage of staff and low morale of the public servants were highlighted as having negative effects on their attitude.

There seems to be a shortage of staff and the poor treatment often experienced by citizens may reflect the fact that public servants are generally overloaded with work and dissatisfied, and therefore express their feelings of stress in their interaction with citizens:

If government can hire many nurses especially at the clinics. We have so many patients who default medication and the rate for TB increases as a result. This is caused by shortage of nurses at the clinic where the patients wait for many hours at the clinic and leave without the medication.

The shortage of staff leads to low morale and "public servants need a way to be encouraged to produce better work" was an opinion expressed by some of the participants. To improve the morale of public servants certain internal mechanisms need to exist within government, which in turn calls for a change in the organisational culture of government departments. Government must take the lead in ensuring an effective response to the needs of public servants, to the ultimate benefit of service delivery. When the morale of public servants is low, their approachability and the ease with which they may be contacted remain in question. When this is the case, the principle of accessibility of services, as well as the sense of openness, transparency and courtesy, might seem non-existent.

As a contribution towards improved attitude of the public servants, some participants emphasised that the behaviour of public servants needs to be monitored regularly, and the supervisors have a vital and consistent role to play. Moreover, various sectors 
in society also have a role to play in instilling sound values and principles in children, especially in their early years ('charity begins at home'). This view is captured in the following comments:

If it [good principles and values] does not come from your home, if you don't see this with your parents how on earth is the university going to change that?

I think we should start small like training children in schools about good manners and about integrity and values ... because if you are valued you will also value [others].

\subsubsection{Redress}

Openness and transparency, the provision of information in terms of the complaints procedure, and accountability and feedback from government in cases where a complaint has been lodged, seem to be insufficient or even absent. There is also an immense power struggle between public servants and citizens, as articulated by a nurse in one clinic:

I have the power and you have nothing so you will do what I tell you to do.

\subsubsection{Information provision, openness and transparency}

The provision of information and the existence of openness and transparency were identified as being closely linked to the principle of access.

In conclusion, the perceptions and experiences of the NPOs regarding public service delivery confirm that the implementation of and compliance with the Batho Pele principles by public servants remain a challenge (Coetzee 2010:84; Hesma \& Roberts 2007:14; Idasa 2010:3-4; Napier 2008:172; RSA DPSA 1997:12; VyasDoorgapersad \& Ababio 2006:392). The Batho Pele principles were adopted as a framework to establish a new service delivery ethic in public service, in line with the human rights as entrenched in the Constitution (RSA 1996). Non-implementation of these principles translates into non-compliance with those human rights, and therefore with the Constitution (RSA 1996) itself.

\subsection{Views on factors promoting the voice of non-profit organisations in service delivery related dialogues}

Choudhury and Ahmed (2002:581) describe the role of the third sector in developing countries (such as South Africa) as being predominantly restrained, undermined and ignored. Similarly the participants confirmed that only a limited platform for dialogue with government is created for the NPOs. 
In cases where NPOs are given the opportunity to voice their concerns with regard to government services, it is often on an individual basis, and non-response from government is reported. There seems to be a tendency by government to endlessly deliberate on service delivery issues rather than to translate the identified solutions into actions. Job-hopping and nepotism (or 'baantiies vir boeties' as one participant referred to the latter) also contribute to poor feedback from government.

There are seven factors identified by the participants and backed up with literature that promote the voice of NPOs. Open channels of communication is an important factor. An open-door system, which allows NPOs to access the right people at all times, would go a long way towards promoting their voice.

Redefinition of the work partnership is useful. Participants noted that the government must realise the value of the NPO sector and its contribution towards public service delivery. One of the participants commented:

If you look at America ... in 2001, a big shift came from donors as well as the government, which is actually putting in more resources and money into NPOs because they know that the NPOs have a bigger basis foundation, a stronger foundation and a purpose, and the sustainability of the NPOs is much longer.

Provision of information is a further factor. The provision of information by government on the rights of NPOs, the complaints management procedure and the relevant contact persons according to the line of command is essential. Although NPOs do not seem to have much of a voice in service delivery related dialogues with government, their voice within the NPO sector itself is much more prominent:

I think we are promoting our voices among other NPOs very well because we network very well ... and the relationship with them is good.

In addition, the collective voice of the third sector is a promoting factor. The coordination of efforts among different bodies within the third sector is a recommended means of promoting its voice as supported by Ghaus-Pasha $(2004: 24,27)$.

The tripartite relationship through building of sound partnerships is an important factor in promoting the voice of the third sector:

I was actually thinking of linking the government with the university with the third sector starting to infuse those.

Making provision for non-profit organisations in legislation is also important:

As we are the third sector ... I think there must also be a law that states that a certain portion of that same money that SARS is getting should go to NPOs and make sure that the allocation is correct. 
There needs to be a shift from non-profit organisations to social enterprises. The advantage of social enterprises is that they seek ways to generate their own funds and become less dependent on government, hence NPOs could promote their voice by transforming into social enterprises. In contrast, the focus in the subsequent section is on the factors highlighted by the participants as hindering the voice of NPOs.

\subsection{Views regarding factors that hinder the voice of non-profit organisations in service delivery related dialogues}

There are numerous factors hindering the voice of the NPOs. Lack of funds is a key factor. One of the defining features of a successful organisation is the ability to effectively and efficiently generate its own revenue and thus remain operational. As such, one of the participants asserted:

[W]e don't have a voice because we don't have money ...

Lack of funds causes the NPOs to become more vulnerable, more dependent, less autonomous and generally submissive to their funders. Confirmatory to the literature review, a lack of financial autonomy was thus also highlighted as one of the contributing factors hindering the voice of NPOs (Ghaus-Pasha 2004:18, 33).

Lack of openness is a further factor as illustrated by the following comment:

There is no openness from both sides of the government and the NPOs - you have to have both.

In addition, misinterpretation of the government-NPO relationship was noted to hinder the voice of NPOs. This is illustrated by a participant's comment:

It seems as if we are working against each other - the NPO against the government. I think that mind-shift must take place with government. Government must understand that this is actually the wing of society that is helping us most or to a great extent.

The lack of buy-in from government was also noted:

Maybe [government] can buy in on the objectives or some of the objectives of the NGO and then they can take it from there, not working against each other but to take hands and partner with them on programmes.

Furthermore a lack of visibility of government departments is illustrated by one participant who stated:

What about the visibility of the departments with the NPO? [government departments] must be more visible, they must reach out to the NPOs.

Public servants are generally seen to be unapproachable and impolite, making NPOs reluctant to voice their concerns. Lack of building capacity is an additional hindering 
factor. This is supported by Ghaus-Pasha $(2004: 18$, 33) who identified capacity constraints as one of the factors that weaken the voice of the third sector. Capacity building emerged as a major concern among several participants. Government involvement in programmes and the provision of training are mechanisms to be used to build capacity. Capable NPO managers could play a major role in improving government accountability and strengthening the voice of citizens in the effort to improve government service.

Lack of engagement by non-profit organisations in decision making processes was also noted. A communication gap exists between NPOs and government. This may lead to the objectivity levels in the decision making processes being compromised. Thus, lack of objectivity and lack of mutual sharing of information between the sectors (third sector and government) could also prevent the voice of the third sector from being heard (Napier 2008:166; Osborn 2010:3; World Bank 2004:8).

\section{CONCLUSION}

The provision of public services as a basic right of the citizens of a country remains the core business of government. It requires consistent efficiency and effectiveness on the part of government in order to respond to the needs of the citizens. Although there are pockets of success in public service delivery, the research findings reveal that more effort from within government structures is needed to improve the overall system. Moreover, a joint effort from various sectors in an increasingly complex world is critical to improved public service delivery. The transformation of public service delivery should be underpinned by principles of inclusive and authentic dialogue, where the voices of all sectors are valued.

However, the voice and current level of participation by NPOs as one of the emergent partners in service delivery related dialogues remain low. NPOs as central to the effort to raise the living standards of the poor and promote the principles of good governance in partnership with government should not be seen as being marginal to the process of public service development and improvement.

In summary, the participants identified several factors that play a role in promoting the voice of NPOs. By creating an open channel of communication, redefining the work partnership and ensuring the provision of information, government can make a major contribution to promoting the voice of NPOs. Higher education can contribute by engaging in reciprocal knowledge sharing and collaboration with both government and the third sector. For their part, NPOs can stand together to serve as the collective voice of the third sector, and be a positive participant in tripartite relationships. Finally, if sufficient provision is made for NPOs in the legislation, and 
there is a shift from NPOs to social enterprises, the voice of the third sector could indeed be made even more audible and their influence will be felt.

Just as there are certain factors that promote the voice of NPOs, so there are certain factors that may have the opposite effect. A lack of funds, resource constraints, a lack of openness, misinterpretation of the government-NPO relationship, a lack of buy-in from government and a lack of visibility of government departments can silence the voice of NPOs and negatively affect the relationship between the third sector and government. Inability of government to instil a two-way consultation process, a lack of approachability and capacity building, along with a lack of engagement of NPOs in decision making processes, particularly in matters directly affecting the citizens, can create further obstacles for NPOs in their endeavour to find their voice and engage in a meaningful and mutually beneficial relationship with government for the ultimate good of the citizens. One of the underlying obstacles leading to the lack of implementation of the Batho Pele principles is the absence of supervision and accountability within government. This calls for an urgent change in the organisational culture of the public service sector. The intention of the research project reported in this chapter was therefore to raise awareness of the Batho Pele principles as central qualities that serve to focus public service on the needs of citizens. Higher education partners can take note of the factors identified in this study and seek ways to collaborate with the partners for sustainable authentic dialogue in the future.

\section{REFERENCES}

Alperstein M. 2007. Getting closer to the community voice in curriculum development - An exploration of the possibilities. Education as Change, 11 (3):59-67.

Berg BL. 2009. Qualitative research methods for the social sciences. Boston, MA: Allyn \& Bacon.

Choudhury E \& Ahmed S. 2002. The shifting meaning of governance: Public accountability of third sector organizations in an emergent global regime. International Journal of Public Administration, 25(4):561-588.

Clark J. 1993. The relationship between the state and the voluntary sector. Washington DC: Human Resources Development and Operation Policy, Wordbank. [Retrieved 25 March $2014]$ http://www-wds.worldbank.org/servlet/WDSContentServer/WDSP/IB/1993/10/01/ 000009265_3961005082045/Rendered/PDF/multi_page.pdf

Coetzee T. 2005. Problematiek en vitdagings van samewerkende regering. Joernaal vir Eietydse Geskiendenis, 30(3):6-90.

Coetzee T. 2010. Co-operative governance and good governance: Reality or myth? Journal for Contemporary History, 35(2):84-106. 
Corbin J \& Strauss A. 2008. Basics of qualitative research: Techniques and procedures for developing grounded theory. 3rd Edition. Thousand Oaks, CA: Sage Publications.

Creswell CM. 2005. What is service learning? In: CM Cress, J Collier \& VL Reitenaver (eds). Learning through servicing: A student guidebook for service-learning across the disciplines. Sterling, VA: Stylus Publishing.

Creswell JW \& Plano Clark VP. 2007. Designing and conducting mixed methods research. Thousand Oaks, CA: Sage Publications.

Du Plessis C \& Van Dyk A. 2013. Integrating the community voice into service learning: Engaging with communities. In: R Osman \& N Petersen (eds). Service learning in South Africa. Cape Town: Oxford University Press Southern Africa. 59-84.

Ghaus-Pasha A. 2004. Role of civil society organizations in governance. Paper presented at the $6^{\text {th }}$ Global Forum on Reinventing Government Towards Participatory and Transparent Governance. Seoul, Republic of Korea, 24-27 May.

Greeff M. 2005. Information collection: Interviewing. In: AS de Vos, H Strydom, CB Fouché \& CSL Delport (eds). Research at grassroots for the social sciences and human service professions. 3rd Edition. Pretoria: Van Schaik. 341-374.

Hesma, D. and Roberts, B. 2007. Batho Pele: Season of discontent. South African Social Attitudes Survey: HSRC Press. [Retrieved 25 November 2014] http://www.hsrc.ac.za/ uploads/pageContent/1607/Batho\%20Pele.pdf

HM Treasury. 2007. The future role of the third sector in social and economic regeneration: final report. Norwich, UK: The Stationary Office. [Retrieved 24 March 2014] https://www. gov.uk/government/uploads/system/uploads/attachment_data/file/228900/7189.pdf

Idasa, LGU (Institute for Democracy in Africa, Local Governance Unit). 2010. The state of local government and service delivery in South Africa: Issues, challenges and solutions. Pretoria: Idasa

Kroukamp H. 1999. Batho Pele: Putting the citizens first in transforming public service delivery in a changing South Africa. International Review of Administrative Sciences, 65(3):327-338.

Krueger RA \& Casey MA. 2009. Focus groups: A practical guide for applied research. 4th Edition. Thousand Oaks, CA: Sage.

Luthuli TB. 2009. From compliance to performance: A leadership challenge in South African public service. Journal of Public Administration, 44(3):460-469.

Macmillan R. 2010. The third sector delivering public services: An evidence review. 7th Edition. Birmingham: Third Sector Research Centre.

Maree K \& J Pietersen. 2007. Sampling. In: K Maree (ed). First steps in research. Pretoria: Van Schaik. 171-181.

McMillan JH \& Schumacher S. 2010. Research in education: Evidence-based inquiry. Boston, MA: Pearson Education.

Mubangizi BC. 2005. Improving public service delivery in the new South Africa: Some reflections. Journal of Public Administration, 40(3):633-648.

Mulaudzi M \& Liebenberg I. 2013. From apartheid to Batho Pele: An exploratory study on service delivery and public participation in Atteridgeville-Saulsville. Journal for Contemporary History, 38(1):142-161. 


\section{FACTORS THAT PROMOTE OR HINDER THE VOICE OF THE THIRD SECTOR IN PUBLIC SERVICE DELIVERY}

Mutahaba G. 2006. African perspectives on public service reform issues and performance. Journal of Public Administration, 41 (2):273-289.

Napier CJ. 2008. Public participation and ward committees: The case of the Tshwane municipality. Journal for Contemporary History, 33(2):163-181.

Ndou SD. 2013. The tripartite alliance as a sine qua non in promoting public interest and accountability in post-apartheid South African governance. Journal of Public Administration, 48(1):189-194.

Nduna NJ. 2007. The community voice on service-learning: A good practice guide for higher education. Education as Change, 11 (3):69-78.

Ngowi HP. 2009. Public private partnership (PPP) in service delivery: Application, reasons, procedures, results and challenges in Tanzanian local government authorities (LGAs). Africagrowth Agenda, April-June:34-36. [Retrieved 13 March 2014] http://reference. sabinet.co.za/webx/access/electronic_journals/afgrow/afgrow_apr_2009_al 1.pdf

Nieuwenhuis J. 2007a. Analysing qualitative data. In: K Maree (ed). First steps in research. Pretoria: Van Schaik. 99-117.

Nieuwenhuis J. 2007b. Qualitative research designs and data gathering techniques. In: K Maree (ed). First steps in research. Pretoria: Van Schaik. 69-97.

Nyamukachi PM. 2004. Options for urban service delivery in South Africa, with special reference to the Tshwane Metropolitan Municipality. Unpublished Master's dissertation. Pretoria: University of Pretoria.

RSA (Republic of South Africa). 1996. Constitution of the Republic of South Africa, Act no 108 of 1996. Pretoria: Government Printers.

RSA (Republic of South Africa). 1997. Higher Education Act 101 of 1997. Pretoria: RSA

RSA DPSA (Republic of South Africa. Department of Public Service and Administration). 1997. White Paper on the Transformation of the Public Service. Pretoria: RSA DPSA

RSA DPSA (Republic of South Africa. Department of Public Service and Administration). 2008. Batho Pele booklet: Guidelines on the functions of the Batho Pele coordinators. Pretoria: RSA DPSA

Sibanda MM. 2011 . Civil society participation in government: Re-examining the third sector in a global perspective. Journal of Public Administration, 46(Special issue 1):814-833.

Thomson AM, Smith-Tolken A, Naidoo A \& Bringle R. 2008. Service learning and community engagement - A cross-cultural perspective. Working Paper Series, International Society for Third-Sector Research. Eighth International Conference, Barcelona, Spain, July 9-12

Vyas-Doorgapersad S \& Ababio EP. 2006. Ethical dilemmas and democratic values: How to reposition institutions for good governance and increased service delivery. Journal of Public Administration, 31 (2.2):385-396.

Wilkins JK. 2001 . Conceptual and practical considerations in alternative service delivery. International Review of Administrative Sciences, 69(2):173-189.

World Bank. 2004. World Development Report: Making services work for poor people. Washington DC: World Bank. 